\title{
Are Fractures To The Bony Cage Protecting the Abdomen Associated with Splenectomy in Cases of Abdominal Trauma? A Cohort Study
}

\section{Amay Banker}

Seth GSMC and KEM Hospital

Martin Gerdin Wärnberg ( $\square$ martin.gerdin@ki.se )

Karolinska Institute

Anita Gadgil

BARC Hospital

\section{Bhakti Sarang}

Terna Medical College and Hospital

\section{Ramlal Prajapati}

Seth GSMC and KEM Hospital

\section{Kapildev Soni}

Apex Trauma Centre, All India Institute of Medical Sciences

Monty Khajanchi

Seth GSMC and KEM Hospital

\section{Research Article}

Keywords: Splenectomy, Splenic trauma, Rib fractures, Vertebral and pelvis fractures.

Posted Date: August 9th, 2021

DOl: https://doi.org/10.21203/rs.3.rs-640046/v1

License: (c) (1) This work is licensed under a Creative Commons Attribution 4.0 International License. Read Full License 


\section{Abstract \\ Background}

The spleen is protected by the ribs anteriorly, the vertebral column posteriorly and the pelvis inferiorly. Fractures to this bony cage may indicate a high-grade splenic injury necessitating splenectomy. We aim to determine whether fractures to the bony cage protecting the abdomen are associated with splenectomy.

\section{Methods}

We performed a subgroup analysis of patients with splenic injury from a prospective trauma registry study named 'Towards Improved Trauma Care Outcomes' (TITCO) in India. Out of the 16047 patients enrolled in the TITCO study, 267 patients with splenic injury were included. Categorical variables were analyzed using the chi square test and logistic regression was used to assess the significance of continuous variables. A multivariate analysis was performed on the factors deemed clinically most significant.

\section{Results}

Patients with a higher grade of splenic injury were more likely to require splenectomy when adjusted for other variables ( $p$ value $<0.05$ ). Patients with fractures to the vertebrae or pelvis had reduced odds of splenectomy on unadjusted analysis [Odds ratio $0.43(0.19-0.94)$ ], but this was not significant when adjusted for other variables.

\section{Conclusion}

In contradiction to our initial hypothesis, we found that fractures to the bony cage protecting the abdomen were not significantly associated with the splenectomy.

\section{Background}

Abdominal trauma constitutes around $10 \%$ of all trauma cases and may have a mortality rate of up to $42 \%$ (1). Spleen is protected in the abdomen by the ribs anteriorly, the vertebral column posteriorly and the pelvis inferiorly. Despite this bony protection, it is the most affected solid organ in blunt abdominal trauma - it is involved in $32-42 \%$ of all abdominal injuries (2-4).

In the mid 1970's there was a paradigm shift in the management of splenic trauma in favor of nonoperative management (NOM), when the spleen's immunological importance and the lifelong risk of overwhelming post splenectomy sepsis was recognized (5). However, a trial of NOM requires intensive 
care facilities and timely availability of operative or minimally invasive interventional modalities. In lowand middle-income countries (LMIC), and in rural hospitals such facilities are not readily available, and so splenectomy is still recommended for moderate to severe splenic injuries (2).

Since appropriate patient selection is crucial for successful management of splenic injuries, sufficient literature has been published to determine factors that are associated with splenectomy (6-19). Amongst these factors, the patient's hemodynamic stability, severity of splenic injury and requirement of blood transfusions are clinically most relevant (2).

In LMIC and in the rural setting, availability of resources like blood banks, intensive care units (ICU), contrast enhanced computed tomography (CECT) scans are infrequent. So, the factor most used for determining the need for urgent splenectomy is the hemodynamic status. The severity of splenic injury is an important determinant in guiding management whenever available. A few authors have used bony injuries as an adjunct to guide decision-making in splenic injury $(20,21)$. While Boris et al found no association between rib fractures and severity of splenic injury, Swaid et al found a clear correlation between severity of pelvic fractures and severity of concomitant splenic injuries $(20,21)$. Teuben et al observed that patients with a femur fracture were more likely to require splenectomy (22).

Any fracture to the bony cage protecting the abdomen implies a high impact trauma. Our hypothesis is that fractures causing injuries to this bony cage may indicate a high-grade splenic injury which may require splenectomy. The association of fractures to the ribs, vertebrae and pelvis with splenectomy has not been studied previously. This would help the surgeon working in rural and limited resource settings, to plan splenectomy in hemodynamically stable patients with an undetermined grade of splenic injury. With this hypothesis in mind, we aimed to determine whether fractures to the bony cage (ribs, pelvis and thoracolumbar vertebrae) protecting the abdomen are associated with splenectomy.

\section{Methodology}

\section{Study Design}

We performed a subgroup analysis of patients with splenic injury from a prospective trauma registry study named 'Towards Improved Trauma Care Outcomes' (TITCO) in India (23). All trauma patients admitted to four public tertiary care institutes in three metropolitan cities between October 2013 and December 2015 were included in the study.

\section{Participants and Data Collection}

Data was collected by dedicated data collectors at each designated center. Patients were followed up until discharge, death or to a maximum of 30 days. The dataset included patient demographics, injuries, serially recorded vital parameters, laboratory parameters, imaging studies, blood transfusions, surgery done, outcome of the patient and length of hospital and intensive care unit (ICU) stay. Data was filtered 
for splenic injury using the ICD-10-CM (International Classification of Diseases, Tenth Revision, Clinical Modification) code - S36.0 (24). Patients without details regarding the operative procedure were excluded from the statistical analysis.

\section{Definitions}

Splenic injuries were graded as per the American Association for the Surgery of Trauma 2018 guidelines based on the imaging records and operative findings (7). Associated injuries were divided into six distinct anatomical regions (head and face, thorax, abdomen, pelvic fractures, extremity fractures and spinal fractures). Thoracic trauma was defined as any rib fracture or underlying hemothorax, pneumothorax or lung contusion. Any fracture of the thoracolumbar vertebrae was counted as vertebral trauma and any fracture of the pelvic bones or sacrum was defined as pelvic trauma.

\section{Statistical Analysis}

Categorical variables were analyzed using the chi square test and a binary logistic regression was developed to assess the significance of continuous variables. Existing literature was reviewed for the clinically most relevant variables associated with the need for splenectomy and logistic regression was used to analyze this. The variables used were, grades of splenic injury, packed cell volume (PCV) transfusions within 24 hours of arrival, intubation within one hour, vitals on arrival, thoracic injury and vertebral or pelvic fractures. Statistical significance was set as $p$ value $<0.05$. Data was analyzed using SPSS 26.0 (Statistical Package for Social Sciences; IBM, Chicago, IL, USA).

\section{Results}

During the study period, data of a total of 16047 patients were included. Out of these, 1134 (7\%) patients suffered from an abdominal injury. There were 267 (23.5\%) patients with

splenic injury in this cohort. Out of these 267 patients, 70 (26\%) required splenectomy. In 20 cases, data regarding splenectomy or any other surgery was missing. So, these cases were excluded from the statistical analysis (Fig. 1). The mean age of the population was 27.9 years with males constituting a vast majority (86\%). The commonest mechanism for splenic trauma was road traffic injuries (60\%). 256 (95\%) patients suffered from blunt abdominal trauma. The patient demographics, epidemiological data and vital parameters on admission are given in Table 1. 
Table 1

Distribution of demographic, physiological and Process variables of the cohort

\begin{tabular}{|lll|}
\hline Variables & $\mathbf{N}=267$ & Missing Data \\
\hline Age & $27.94( \pm 14)$ & - \\
Sex & $230(86.1 \%)$ & \\
Female & $37(13.9 \%)$ & - \\
\hline Type of Injury & & \\
Blunt & $256(95.9 \%)$ & - \\
Penetrating & $11(4.1 \%)$ & \\
Mechanism of Injury & & \\
Road Traffic Accident & $161(60.3 \%)$ & \\
Fall & $66(24.7 \%)$ & \\
Railway Accident & $15(5.6 \%)$ & \\
Assault & $20(7.5 \%)$ & - \\
Other & $5(1.9 \%)$ & \\
Transfer from Other Hospital & & \\
Mode of Transport & $143(53.6 \%)$ & \\
Ambulance & $139(52.1 \%)$ & \\
Police & $40(15 \%)$ & \\
Private Car & $52(19.5 \%)$ & \\
Taxi & $36(13.4 \%)$ & \\
\hline
\end{tabular}




\begin{tabular}{|lll|}
\hline Variables & $\mathbf{N}=\mathbf{2 6 7}$ & Missing Data \\
\hline Vitals on Arrival & $110(99-124)$ & - \\
SBP (mmHg) & $96(80.5-110.75)$ & $4(1.4 \%)$ \\
HR (Beats Per Minute) & $18(16-20)$ & $3(1.1 \%)$ \\
RR (Per Minute) & $100(99-100)$ & $18(6.7 \%)$ \\
Spo2 (\%) & $33(12.3 \%)$ & $28(10.4 \%)$ \\
GCS & $10(3.8 \%)$ & $17(6.4 \%)$ \\
Severe (<8) & $207(77.5 \%)$ & \\
Moderate (9-12) & & \\
Mild (13-15) & $17(9-25)$ & $96(20.9 \%)$ \\
\hline Injury Severity Score (ISS) & 210 (70-673) & $9.3 \%)$ \\
\hline Time from Injury to Admission, minutes & & \\
\hline Continuous Values Are Listed as Median (Interquartile Range) And Categorical Variables as Count \\
(Percentage). Age Is Listed as Mean ( \pm Standard Deviation) & \\
SBP Indicates Systolic Blood Pressure; HR, Heart Rate; RR, Respiratory Rate; GCS, Glasgow Coma \\
\hline Scale; SPO2, Oxygen Saturation.
\end{tabular}

The liver was the most common organ concomitantly injured followed by the intestines. Injury to thorax was noted in 119 (44.5\%) cases. Out of these, rib fractures were noted in 81 cases and fractures of the thoracolumbar vertebrae or pelvis were noted in 58 (21.7\%) of the patients (Fig. 2).

Out of the 267 patients, 251 (94\%) underwent focused assessment with sonography in trauma (FAST) examination; a positive result was seen in $43 \%$ of the tests. X-rays were performed for 257 (96\%) patients. A CECT scan was ordered for $237(88.8 \%)$ cases. Out of the 30 patients not undergoing a CECT scan, $x$ rays were available for 26 patients. Thoracic, vertebral, or spinal fractures were diagnosed using $x$-rays in these patients. In the remaining 4 patients, thoracic injury in the form of hemothorax was diagnosed on extended FAST examination in one patient.

In this cohort of splenic injuries $(n=267), 12$ patients underwent an emergency surgery within 1 hour of arrival and 102 more patients required operative management within 24 hours of admission. The indications of surgery were diverse, and splenectomy was performed in $70(26 \%)$ cases. $132(49 \%)$ patients required PCV transfusions within 24 hours of admission. Mortality was noted in $3(8 \%)$ of grade 1 and $6(12 \%)$ of grade 2 injuries. In contrast, mortality was noted in $9(28 \%)$ grade 5 splenic injuries. There were overall 41 (15\%) deaths in the study cohort (Table 2). 


\begin{tabular}{|c|c|c|}
\hline Investigation and Surgery & $n=267$ & MISSING \\
\hline Hemoglobin & $10.7(9.07-12.83)$ & - \\
\hline Hematocrit & $29.4(0-37.1)$ & - \\
\hline X-Ray & 257 (96\%) & $10(3.7 \%)$ \\
\hline FAST & $251(94 \%)$ & $16(5.9 \%)$ \\
\hline Positive & $110(43.8 \%)$ & \\
\hline CT scan & $237(88.8 \%)$ & $30(11.2 \%)$ \\
\hline Grade 1 & $34(12.7 \%)$ & \\
\hline Grade 2 & $61(22.8 \%)$ & \\
\hline Grade 3 & $60(22.4 \%)$ & \\
\hline Grade 4 & $47(17.6 \%)$ & \\
\hline Grade 5 & $35(13.1 \%)$ & \\
\hline Surgery & $12(4.4 \%)$ & - \\
\hline $\begin{array}{l}\text { within } 1 \text { hour } \\
\text { from } 1 \text { to } 24 \text { hours }\end{array}$ & $102(38.2 \%)$ & \\
\hline Type of surgery & $20(7.4 \%)$ & - \\
\hline EEL (unspecified) & $70(26.2 \%)$ & \\
\hline EEL + Splenectomy & $16(5.9 \%)$ & \\
\hline EEL + Other organ repair & $8(2.9 \%)$ & \\
\hline \multicolumn{3}{|l|}{ Others } \\
\hline PCV transfused & $52(19.4 \%)$ & - \\
\hline within 1 hour & $80(29.9 \%)$ & \\
\hline \multicolumn{3}{|l|}{ from 1 to 24 hours } \\
\hline Length of hospital stay, days & $7(4-14)$ & $1(0.3 \%)$ \\
\hline Mortality & $41(15.3 \%)$ & - \\
\hline \multicolumn{3}{|c|}{$\begin{array}{l}\text { Continuous values are listed as median (interquartile range) and categorical variables as count } \\
\text { (percentage). }\end{array}$} \\
\hline \multicolumn{3}{|c|}{$\begin{array}{l}\text { EEL-Emergency exploratory laparotomy; FAST Focused assessment with sonography in trauma; CT } \\
\text { computed tomography; PCV-packed cell volume; USG- Ultrasonography }\end{array}$} \\
\hline
\end{tabular}


$26(82 \%)$ of the grade 5 and $31(67 \%)$ of grade 4 splenic injuries required operative management. All the cases of Grade 1 splenic injuries were conservatively managed (Figure 3).

Fractures of the thoracolumbar vertebrae or the pelvis, along with a splenic injury, were significantly associated with reduced odds of splenectomy. No similar association was present between rib fracture and other thoracic injuries and splenectomy. Injury severity score (ISS) was significantly higher in the patients undergoing splenectomy (Table 3). 
Table 3

Unadjusted Analysis ( $\mathrm{n}=247$ )

\begin{tabular}{|c|c|c|c|c|}
\hline & $\begin{array}{l}\text { No Splenectomy ( } \\
=177 \text { ) }\end{array}$ & $\begin{array}{l}\text { Splenectomy } \\
(\mathrm{N}=70)\end{array}$ & $\begin{array}{l}\mathrm{P} \\
\text { Value }\end{array}$ & $\begin{array}{l}\text { Odds Ratio } \\
(95 \% \mathrm{Cl})\end{array}$ \\
\hline Age (years) & 29 & 25 & 0.046 & $0.97(0.95-1.0)$ \\
\hline Males (\%) & $147(81 \%)$ & $66(94 \%)$ & 0.021 & $\begin{array}{l}3.36(1.12- \\
9.94)\end{array}$ \\
\hline Blunt trauma (\%) & $169(95 \%)$ & $70(100 \%)$ & 0.071 & - \\
\hline $\begin{array}{l}\text { Intubated within one hour of } \\
\text { arrival (\%) }\end{array}$ & $28(16 \%)$ & $23(32 \%)$ & 0.003 & $\begin{array}{l}2.6(1.37- \\
4.94)\end{array}$ \\
\hline $\begin{array}{l}\text { Transfusion within } 24 \text { hours of } \\
\text { arrival (\%) }\end{array}$ & $54(30 \%)$ & $39(54 \%)$ & $<.001$ & $\begin{array}{l}2.86(1.62- \\
5.06)\end{array}$ \\
\hline Grade $1(\%)$ & $32(18 \%)$ & 0 & - & - \\
\hline Grade $2(\%)$ & $54(30 \%)$ & $3(4 \%)$ & - & - \\
\hline Grade $3(\%)$ & $48(27 \%)$ & $10(14 \%)$ & 0.032 & $\begin{array}{l}0.44(0.21- \\
0.94)\end{array}$ \\
\hline Grade 4 (\%) & $15(8 \%)$ & $31(45 \%)$ & 0.000 & $\begin{array}{l}8.58(4.22- \\
17.43)\end{array}$ \\
\hline Grade $5(\%)$ & $6(3 \%)$ & $26(37 \%)$ & 0.000 & $\begin{array}{l}16.84(6.52- \\
43.43)\end{array}$ \\
\hline Missing grade (\%) & $22(12 \%)$ & 0 & - & - \\
\hline Thoracic injury (\%) & $84(47 \%)$ & $29(41 \%)$ & 0.391 & $\begin{array}{l}0.78(0.44- \\
1.37)\end{array}$ \\
\hline Vertebral or pelvis fracture (\%) & $45(25 \%)$ & $9(13 \%)$ & 0.031 & $\begin{array}{l}0.43(0.19- \\
0.94)\end{array}$ \\
\hline Vitals on arrival & 112 & 102 & 0.008 & $\begin{array}{l}0.98(0.97- \\
0.99)\end{array}$ \\
\hline $\mathrm{SBP}(\mathrm{mmHg})$ & 96 & 100 & 0.096 & \\
\hline HR (bpm) & 18 & 18 & 0.546 & $1.02)$ \\
\hline RR (/minute) & 97 & 93 & 0.024 & $\begin{array}{l}0.97(0.90- \\
1.05)\end{array}$ \\
\hline $\mathrm{SpO}_{2}(\%)$ & & & & $\begin{array}{l}0.97(0.94- \\
0.99)\end{array}$ \\
\hline Injury severity score (ISS) & 16 & 20 & 0.005 & $\begin{array}{l}1.04(1.01- \\
1.08)\end{array}$ \\
\hline $\begin{array}{l}\text { Time from injury to admission } \\
\text { (minutes) }\end{array}$ & 948 & 1239 & 0.565 & - \\
\hline
\end{tabular}




\begin{tabular}{|c|c|c|c|c|}
\hline & $\begin{array}{l}\text { No Splenectomy ( } \mathrm{N} \\
=177)\end{array}$ & $\begin{array}{l}\text { Splenectomy } \\
(N=70)\end{array}$ & $\begin{array}{l}\mathrm{P} \\
\text { Value }\end{array}$ & $\begin{array}{l}\text { Odds Ratio } \\
\text { (95\% Cl) }\end{array}$ \\
\hline Lab investigations & 10.9 & 10.0 & 0.056 & $0.90(0.82-$ \\
\hline $\begin{array}{l}\text { Hemoglobin }(\mathrm{mg} / \mathrm{dL}) \\
\text { Hematocrit }\end{array}$ & 21 & 25 & $\begin{array}{l}0 . \\
147\end{array}$ & $\begin{array}{l}1.01(0.99- \\
1.03)^{(1.96}\end{array}$ \\
\hline
\end{tabular}

Majority of patients in the splenectomy group had lower systolic blood pressure and oxygen saturation at arrival. More patients in the splenectomy group required transfusion within 24 hours of admission ( $p$ value $<0.001$ ). A higher grade of splenic injury (grade 4 and grade 5 ) was associated with splenectomy ( $p$ value $<0.001$ ). Male sex ( $p$ value 0.021 ) and requirement of intubation and mechanical ventilation within 1 hour of arrival ( $p$ value 0.003 ) were other significant predictors of splenectomy on unadjusted analysis.

On adjusted analysis, grade 4 and grade 5 splenic injuries were significantly associated with splenectomy ( $p$ value $<0.05)$. No other variables were statistically significant (Table 4$)$.

Table 4

Adjusted analysis ( $n=247)$, with Splenectomy as the Outcome

\begin{tabular}{|lll|}
\hline & Odds Ratio (95\% Cl) & P Value \\
\hline Transfusion within 24 hours of arrival & $1.56(0.64-3.79)$ & 0.325 \\
\hline Intubated within one hour & $1.75(0.49-6.2)$ & 0.384 \\
\hline Grade 3 & $8(1.86-35.33)$ & 0.005 \\
\hline Grade 4 & $91(20.73-401.22)$ & 0.000 \\
\hline Grade 5 & $170(33.12-876.49)$ & 0.000 \\
\hline Thoracic injury & $0.85(0.35-2.03)$ & 0.720 \\
\hline Vertebral or pelvis fracture & $1.15(0.39-3.43)$ & 0.791 \\
Vitals on arrival & $0.99(0.97-1.01)$ & 0.409 \\
Systolic Blood Pressure & $0.96(0.91-1.01)$ & 0.118 \\
$\mathrm{SpO}_{2}$ & & \\
\hline
\end{tabular}

\section{Discussion}


The present study analysed the data of patients with splenic injury, admitted to four tertiary care hospitals in India, with the aim to understand the association of fractures to the bony cage protecting the abdomen with splenectomy. Thoracic injury was the most frequently encountered concomitant injury in patients with splenic trauma (44.5\%), but no significant association was noted between thoracic injury and splenectomy in the present study. Fractures to the pelvis or vertebral column were associated with reduced odds of splenectomy on unadjusted analysis [OR $0.43(0.19-0.94) ; p$ value 0.03 ]. However, this statistical significance was lost when adjusted for other variables.

These findings contradict our initial hypothesis that fractures to the bony cage may result in a more severe splenic injury. From our analysis we see that the fractures to the bony cage cannot be used to determine the need for splenectomy. One reason for this could be due to the selection of all the rib and pelvic fractures and not side specific ones. Another reason may be that the pelvis and vertebrae take the brunt of the trauma leading to fracture and thus the kinetic energy of the trauma dissipates, protecting the underlying spleen. Further research and studies primarily designed to look into the association of fractures to bony cage protecting the abdomen with splenectomy are required before this finding can be considered.

In our study, a higher grade of splenic injury was significantly associated with splenectomy ( $p$ value< 0.05 for Grade 3 to 5 lesions). On adjusting for other variables, the grade of splenic injury remained significantly associated with splenectomy. However, patient's conditions may necessitate an emergent transfer to the operating room without the opportunity to define the grade of the splenic lesions (25). According to the recently published World Society of Emergency Surgery guidelines, the optimal strategy should take into consideration not only the grade of splenic injury but the patient's hemodynamic status and concomitant injuries as well (2).

Our study shows that systolic blood pressure and oxygen saturation levels on arrival were significantly associated with splenectomy on unadjusted analysis. We also observed that patients who required blood transfusions were at a higher risk of undergoing splenectomy on unadjusted analysis. Out of the 70 patients requiring splenectomy, 39 patients had received a blood transfusion within 24 hours of admission ( $p$ value 0.001). This finding corroborates many studies that have shown that the requirement of blood transfusions is independently associated with splenectomy in cases of blunt abdominal trauma $(2,15,26,27)$. However, both these variables (blood transfusions and vitals on arrival) lacked statistical significance in our adjusted analysis. We believe that unavailability of ICU beds, intensive care monitoring and blood and blood products, may have led to a lower threshold for splenectomy. In addition, lack of departmental protocols and surgeon biases may have led to splenectomies being performed despite a stable hemodynamic status and non-administration of blood transfusion.

Like in previous studies, we also observed that a higher ISS score was significantly associated with splenectomy on unadjusted analysis (28-30). However, ISS and other trauma assessment scores are usually used to analyze the outcomes in trauma patients and have little role in guiding patient management. The present study found splenic injury to be more common between the age of 20-50 
years with a male preponderance. While lower age and male sex were significantly associated with splenectomy in unadjusted analysis, these findings are unlikely to be of any significance clinically. Therefore, these variables were not included in the adjusted analysis.

\section{Limitations}

A limitation of this study was the unavailability of data regarding splenic artery embolization and side specific rib fractures. small sample size of patients undergoing splenectomy and further studies which primarily look for associations of fractures to the bony cage protecting the abdomen with splenectomy are needed.

\section{Conclusion}

In contradiction to our initial hypothesis, we found that fractures to the bony cage protecting the abdomen were not significantly associated with the splenectomy.

\section{Abbreviations}

LMIC- Low- and Middle- Income Countries

TITCO- Towards Improved Trauma Care Outcomes

ICU - intensive care units

CECT- contrast enhanced computed tomography

PCV - packed cell volume

FAST - focused assessment with sonography in trauma

ISS - Injury Severity Score

\section{Declarations}

Funding. The TITCO funding agencies were the Swedish National Board of Health and Welfare and the Laerdal Foundation. The authors declare that these agencies had no influence on the conceptualisation or findings of this study.

Conflicts of Interest. Authors A.B, M.G.W, A.G, B.S, R.P, K.S, and M.K declare that they have no conflicts of interest to disclose.

Ethics Approval. Waiver of consent was obtained by all institutional review boards. The institutional ethics committee of all three participating hospitals LTMGH (IEC/11/13 dated 26 Jul 2013), KEM 
(IEC(I)/out/222/14 dated 4 Mar 2014) and SSKM (IEC/279 dated 21 Mar 2013) individually approved the collation of the database.

Statement on Ethical Standard: All procedures performed were in accordance with the ethical standards of the institutional and national research committee and with the 1964 Helsinki Declaration and its later amendments.

Consensus and Publication Statement: This is a subgroup analysis of patients with splenic injury from a prospective trauma registry study named 'Towards Improved Trauma Care Outcomes' (TITCO) in India. [Roy N, Gerdin M, Ghosh S, et al (2016) 30-day in-hospital trauma mortality in four urban university hospitals using an Indian Trauma Registry. World J Surg 40:1299-1307]

This analysis and manuscript has not been published and is neither under consideration for publication elsewhere.

Availability of data and materials: The datasets used and/or analysed during the current study available from the corresponding author on reasonable request.

\section{Author Contributions.}

A.B, R.P and M.K conceptualized the study and also wrote the main manuscript text.

M.W, K.S supervised the statistical analysis and helped with the final draft of the manuscript.

A.G, B.S performed critical review of the manuscript and prepared the tables and figures of the manuscript.

Acknowledgment. Not applicable.

\section{Disclosure Statement}

The TITCO funding agencies were the Swedish National Board of Health and Welfare and the Laerdal Foundation. The authors declare that these agencies had no influence on the conceptualization or findings of this study. All authors have no conflicts of interest to disclose.

\section{References}

1. Hildebrand DR, Ben-Sassi A, Ross NP, ï»¿ ¿Macvicar R, Frizelle, F. A., Watson A. J.M. Modern management of splenic trauma. BMJ (Online) 2014; 348.

2. Coccolini F, Montori G, Catena F, Kluger Y, Biffl W, Moore E, et al. Splenic trauma: WSES classification and guidelines for adult and pediatric patients. World J Emerg Surg. 2017; $12: 1$.

3. Hady HR, Łuba M, Myśliwiec P, Trochimowicz L, Łukaszewicz J, Zurawska J, et al. Surgical management in parenchymatous organ injuries due to blunt and penetrating abdominal traumas - 
The authors' experience. Adv Clin Exp Med. 2012; 21:193-200

4. Amico F, Anning R, Bendinelli C, Balogh ZJ, Leppäniemi A, Aparicio-Sánchez D, et al. Grade III blunt splenic injury without contrast extravasation - World Society of Emergency Surgery Nijmegen consensus practice. World J Emerg Surg. 2020; 15:46

5. Moore FA, Davis JW, Moore EE, Cocanour CS, West MA, Mclntyre RC. Western trauma association (WTA) critical decisions in trauma: Management of adult blunt splenic trauma. J. Trauma - Inj. Infect. Crit. Care. 2008; 65:1007-1011

6. Bala M, Edden Y, Mintz Y, Kisselgoff D, Gercenstein I, Rivkind Al, et al. Blunt splenic trauma: Predictors for successful non-operative management. Isr Med Assoc J. 2007; 9:857-861

7. Kozar RA, Crandall M, Shanmuganathan K, Zarzaur BL, Coburn M, Cribari C, et al. Organ injury scaling 2018 update: Spleen, liver, and kidney. J Trauma Acute Care Surg. 2018; 85:1119-1122.

8. Rajani RR, Claridge JA, Yowler CJ, Patrick P, Wiant A, Summers JI, et al. Improved outcome of adult blunt splenic injury: A cohort analysis. Surgery. 2006; 140:625-632.

9. ï» ¿ Haan JM, Bochicchio G V., Kramer N, Scalea TM. Nonoperative management of blunt splenic injury: A 5-year experience. J. Trauma - Inj. Infect. Crit. Care. 2005; 58:492-498.

10. Haan JM, Biffl W, Knudson MM, Davis KA, Oka T, Majercik S, et al. Splenic Embolization Revisited: A Multicenter Review. J. Trauma - Inj. Infect. Crit. Care. 2004; 56:542-547

11. Wahl WL, Ahrns KS, Chen S, Hemmila MR, Rowe SA, Arbabi S. Blunt splenic injury: Operation versus angiographic embolization. Surgery. 2004; 136:891-899.

12. Dent D, Alsabrook G, Erickson BA, Myers J, Wholey M, Stewart R, et al. Blunt splenic injuries: High nonoperative management rate can be achieved with selective embolization. J. Trauma - Inj. Infect. Crit. Care. 2004; 56:1063-1067

13. Haan JM, Scott J, Boyd-Kranis RL, Ho S, Kramer M, Scalea TM. Admission angiography for blunt splenic injury: advantages and pitfalls. J Trauma. 2001; 51:1161-1165

14. ï»¿ Mitchell TA, Wallum TE, Becker TE, Aden JK, Bailey JA, Blackbourne LH, et al. Nonoperative management of splenic injury in combat: 2002-2012. Mil Med. 2015; 180:29-32

15. A. Omert L, Salyer D, Dunham CM, Porter J, Silva Al, Protetch J. Implications of the "contrast blush" finding on computed tomographic scan of the spleen in trauma. J Trauma. 2001; 51:272-278.

16. Becker CD, Spring P, Glattli A, Schweizer W. Blunt splenic trauma in adults: Can CT findings be used to determine the need for surgery? Am J Roentgenol. 1994; 162:343-347.

17. Schurr MJ, Fabian TC, Gavant M, Croce MA, Kudsk KA, Minard G, et al. Management of blunt splenic trauma: Computed tomographic contrast blush predicts failure of nonoperative management. J. Trauma - Inj. Infect. Crit. Care. 1995; 39:507-513

18. Beuran M, Gheju I, Venter MD, Marian RC, Smarandache R. Non-operative management of splenic trauma. J Med Life. 2012; 5:47-58.

19. Malhotra AK, Latifi R, Fabian TC, Ivatury RR, Dhage S, Bee TK, et al. Multiplicity of solid organ injury: Influence on management and outcomes after blunt abdominal trauma. J Trauma. 2003; 52:925- 
929

20. Swaid F, Peleg K, Alfici R, Oded O, Adi G, Boris K. A comparison study of pelvic fractures and associated abdominal injuries between pediatric and adult blunt trauma patients. J Pediatr Surg. $2017 ; 52: 386-389$

21. Boris K, Forat S, Itamar A, Oded O, Kobi P, Adi G, al. Increasing number of fractured ribs is not predictive of the severity of splenic injury following blunt trauma: An analysis of a National Trauma Registry database. Injury. 2014; 45:855-858

22. Teuben MPJ, Spijkerman R, Blokhuis TJ, Pfeifer R, Teuber H, Pape HC, et al. Safety of selective nonoperative management for blunt splenic trauma: The impact of concomitant injuries. Patient Saf Surg. 2018; $12: 32$

23. Roy N, Gerdin M, Ghosh S, Gupta A, Kumar V, Khajanchi M, et al. 30-day in-hospital trauma mortality in four urban university hospitals using an Indian Trauma Registry. World J Surg. 2016; 40:12991307

24. Organization WH. ICD-10: international statistical classification of diseases and related health problems: tenth revision. https://apps.who.int/iris/handle/10665/42980

25. Peitzman AB, Heil B, Rivera L, Federle MB, Harbrecht BG, Clancy KD, et al. Blunt splenic injury in adults: Multi-institutional study of the Eastern Association for the Surgery of Trauma. J. Trauma - Inj. Infect. Crit. Care. 2000; 49:177-189

26. Böyük A, Gümüş $M$, Önder A, Kapan M, Aliosmanoğlu I, Taşkesen F, et al. Splenic injuries: Factors affecting the outcome of non-operative management. Eur J Trauma Emerg Surg. 2012; 38:269-274.

27. Jiménez-García AD, Cardiel-Marmolejo LE, Cerón-García CG, Durán-Ortiz S. Splenectomy in abdominal trauma in the General Hospital of Balbuena from January 2010 to December 2014. Rev Médica del Hosp Gen México. 2018; 81:35-40.

28. Mclntyre LK, Schiff M, Jurkovich GJ, Weigelt J, Asensio JA, Cogbill TH, et al. Failure of nonoperative management of splenic injuries: Causes and consequences. Arch. Surg. 2005; 140:563-569

29. Hunt JP, Lentz CW, Cairns BA, Ramadan, FM, Smith DL, Rutledge R, et al. Management and outcome of splenic injury: The results of a five-year statewide population-based study. Am Surg. 1996; 62:911-917

30. Konstantakos AK, Barnoski AL, Plaisier BR, Yowler CJ, Fallon WF, Malangoni MA. Optimizing the management of blunt splenic injury in adults and children. Surgery. 1999; 126:805-813

\section{Figures}




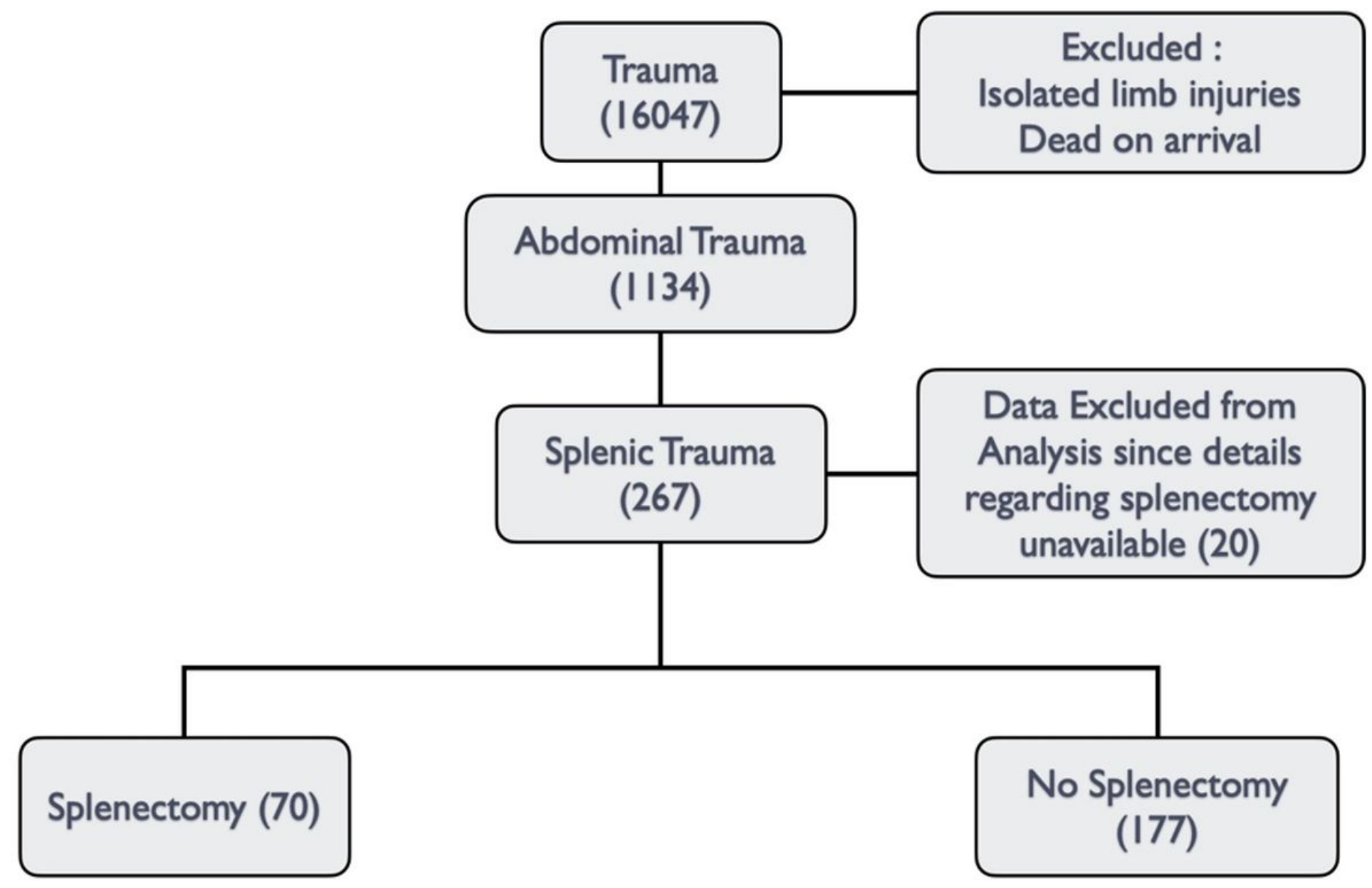

Figure 1

Recruitment Algorithm 


\section{Associated Injuries ( $n=267$ )}

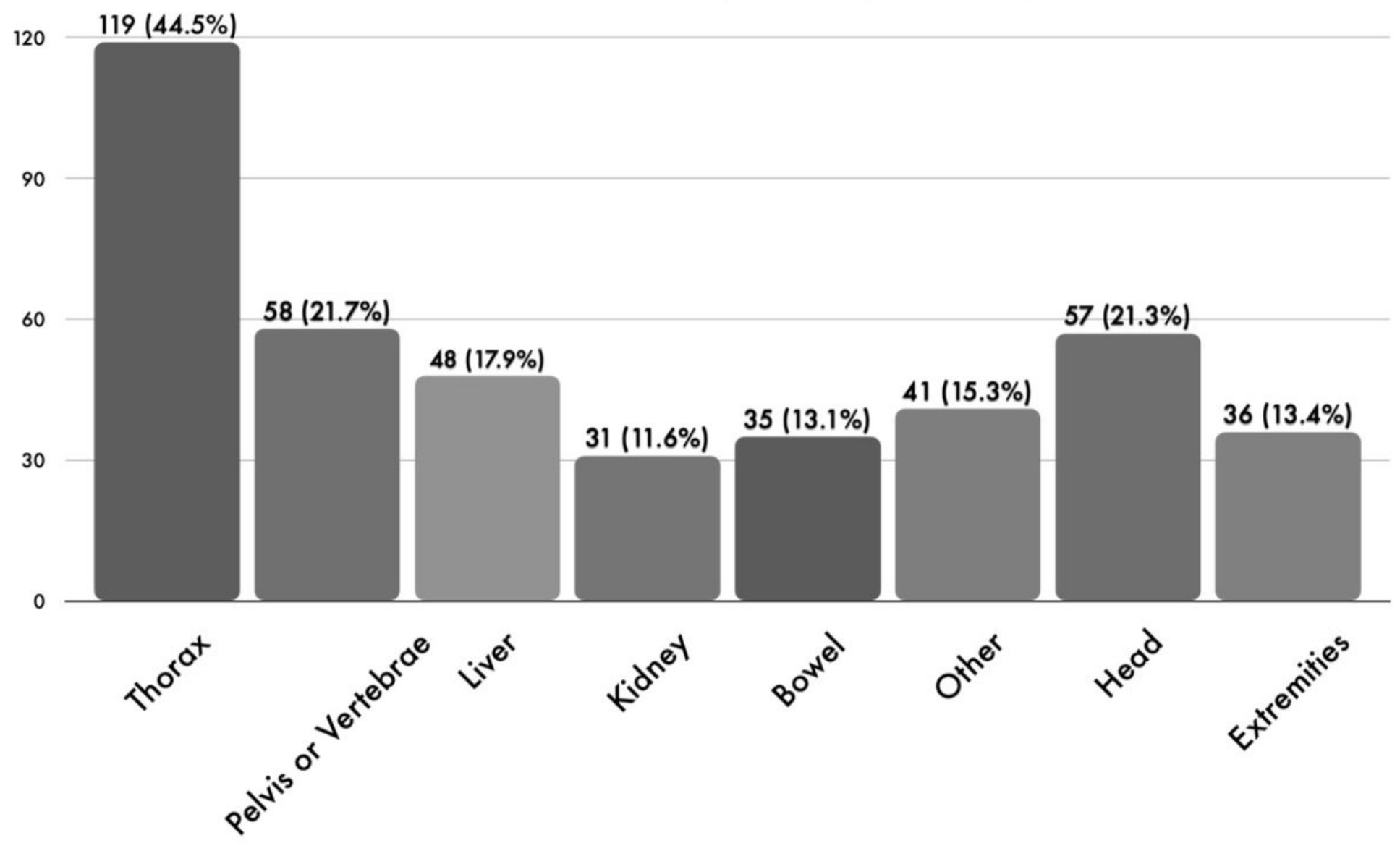

Figure 2

Associated Injuries 
No Splenectomy

Splenectomy

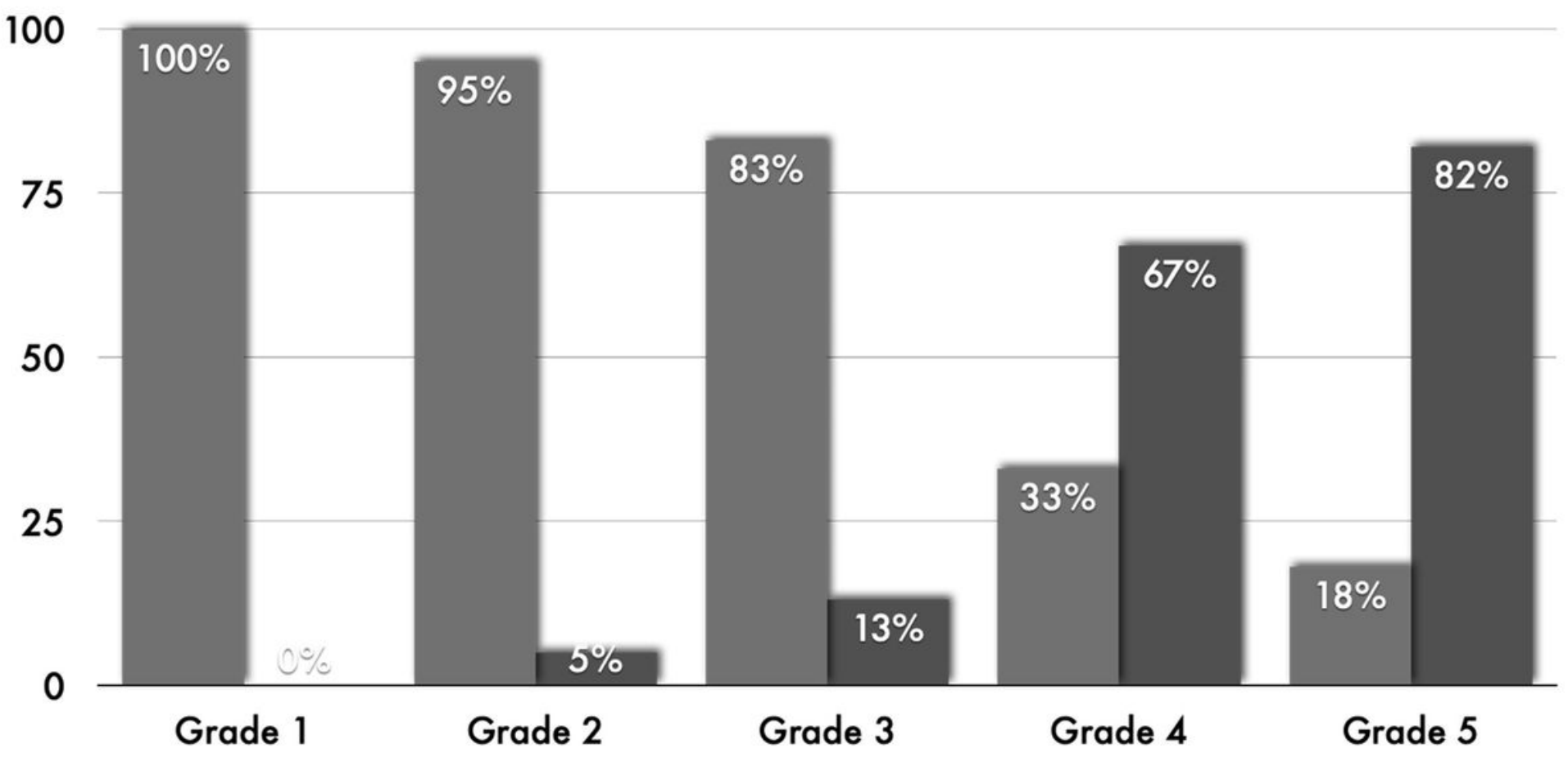

Figure 3

Association of splenectomy with grade of splenic injury 